\title{
EVALUASI EFEKTIFITAS SISTEM PENGENDALIAN INTERNAL PENGOLAHAN ASET (STUDI PADA BADAN KEUANGAN DAN ASET DAERAH KOTA SORONG)
}

\author{
Calvin Liawan,SE., M.Sc \\ Program Studi Sarjana Terapan Akuntansi Keuangan Publik \\ Politeknik Katolik Saint Paul Sorong
}

\begin{abstract}
ABSTRAK
Penelitian ini bertujuan untuk menyusun sistem pengendalian internal aset yang baik dan benar sehingga penulis dapat melakukan pembuatan sistem pengendalian internal aset dengan baik dan benar. Penelitian menggunakan metode teknik studi kepustakaan, kuesioner dan wawancara serta penggunaan data dari literatur-literatur. Hasil penelitian menunjukan bahwa, sistem pengendalian internal aset sangatlah penting karena jika sistem pengendalian internal aset tidak berjalan dengan baik atau semestinya maka akan berpengaruh pada laporan keuangan aset (neraca).
\end{abstract}

Kata Kunci: Sistem pengendalian internal aset

\section{BAB I PENDAHULUAN}

\section{Latar Belakang}

Pengelolaan aset daerah pada BPKAD Kota Sorong merupakan kewenangan pemerintah daerah berdasarkan UndangUndang 23 tahun 2014 tentang Pemerintah Daerah dan Undang-Undang Nomor 33 Tahun 2004 tentang Perimbangan Keuangan antara Pemerintah Pusat dan Pemerintah Daerah untuk menjalankan roda pemerintahan dan pengelolaan aset daerah dengan asas otonomi daerah. Dalam upaya untuk memperkuat pengelolaan keuangan negara, setiap pejabat yang menyajikan laporan keuangan diharuskan untuk memberi pernyataan tanggungjawab atas laporan keuangan yang bersangkutan yang menyatakan bahwa laporan keuangan telah disusun berdasarkan sistem pengendalian intern yang memadai dan informasi yang termuat pada laporan keuangan telah disajiakan sesuai dengan SAP. Pengendalian intern tersebut sekurang-kurangnya memenuhi kriteria sebagai berikut: terciptanya lingkungan pengendalian yang sehat, terselenggaranya penilaian risiko, terselenggaranya aktivitas pengendalian, terselenggaranya sistem informasi dan komunikasi serta terselenggaranya kegiatan pemantauan pengendalian.

\section{Rumusan Masalah}

Rumusan masalah dalam penelitian ini yaitu untuk mengevaluasi efektifitas sistem pengendalian intern pengelolaan aset yang meliputi lima (5) komponen menurut Peraturan Pemerintah Nomor 60 Tahun 2008 yaitu: Lingkungan Pengendalian, Penilaian Risiko, Aktivitas Pengendalian, Informasi dan Komunikasi, dan Pemantauan.

\section{Tujuan dan Manfaat Penelitian}

Tujuan penelitian ini adalah untuk mengevaluasi efektifitas sistem pengendalian intern pengelolaan aset yang ada di Inspektorat dan Badan Pengelolaan Keuangan dan Aset Daerah Pemerintah Kota Sorong. Hasil penelitian ini dapat memberikan manfaat dan sumbangan pikiran kepada; Pemerintah Kota Sorong dalam menentukan kebijakan sistem pengendalian intern yang diterapkan terhadap pengelolaan aset tetap daerah agar tertib, efektif dan efisien. Bagi Kalangan Akademisi Penelitian ini diharapkan dapat dijadikan acuan oleh penelitian selanjutnya yang membutuhkan informasi sebagai bahan perbandingan untuk penelitian sejenis.

\section{Batasan Masalah}

Untuk memudahkan penyusunan dalam membahas pokok pikiran secara jelas, perlu ditentukan adanya pembatasan masalah. 
Dalam hal ini, permasalahan hanya terbatas pada sistem pengendalian intern atas aset tetap daerah yang di terapkan oleh Badan Pengelolaan Keuangan dan Aset Daerah Kota Sorong.

\section{BAB II TINJAUAN PUSTAKA}

Pengendalian Intern merupakan bagian dari masing-masing sistem yang dipergunakan sebagai prosedur dan pedoman pelaksanaan operasional perusahaan atau organisasi tertentu. Sedangkan Sistem Pengendalian Intern merupakan kumpulan dari pengendalian intern yang terintegrasi, berhubungan dan saling mendukung satu dengan yang lainnya.

Menurut Mulyadi dalam bukunya "Sistem Akuntansi" mengatakan bahwa Sistem pengendalian intern meliputi struktur organisasi, metode dan ukuran-ukuran yang dikoordinasikan untuk menjaga kekayaan organisasi, mengecek ketelitian yang keandalan data akuntansi, mendorong efisiensi dan mendorong dipatuhinya kebijaksanaan manajemen.

Barang milik daerah merupakan komponen penting yang harus dipertanggungjawabkan karena pos ini dikeluarkan melalui mata anggaran belanja dalam belanja daerah. Oleh karenanya, pengeluaran atas barang milik daerah harus dipertanggungjawabkan dalam LRA, sedangkan nilai keseluruhan barang milik daerah yang berada dalam penguasaan SKPD dilaporkan dalam neraca pemerintah daerah. Informasi mengenai barang milik daerah yang ada dalam penguasaan SKPD dilaporkan dalam neraca pemerintah daerah. Informasi mengenai barang milik daerah yang akurat, dapat dipercaya, andal, dan dapat tepat waktu hanya bisa disajikan jika penatausahaan terhadap barang-barang tersebut dilakukan secara sistematik dan memadai. Untuk memberikan jaminan bahwa laporan barang milik daerah telah dilaksanakan dengan baik, perlu dibangun sistem pengendalian internal (SPI) atas hal tersebut.

Pengertian aset tetap menurut SAP adalah "aset berwujud yang mempunyai masa manfaat lebih dari 12 (dua belas) bulan untuk digunakan dalam kegiatan pemerintah atau dimanfaatakan oleh masyarakat umum".

\begin{tabular}{|c|c|}
\hline $\begin{array}{l}\text { Menurut } \\
\text { ngaruh }\end{array}$ & $\begin{array}{c}\text { Halim } \\
\text { manajemen }\end{array}$ \\
\hline
\end{tabular}

optimalisasi" mengatakan bahwa Aset tetap adalah aset berwujud yang mempunyai masa manfaat lebih dari satu periode akuntansi untuk digunakan dalam kegiatatan pemerintah atau dimanfaatkan oleh masyarakat umum. Aset tetap terdiri dari:

- Tanah

- Peralatan dan Mesin

- Gedung dan Bangunan

- Jalan, Irigasi dan Jaringan

- Aset Tetap Lainnya

- Bangunan Dalam Pengerjaan

Peraturan Pemerintah Nomor 71 Tahun 2010 tentang Standar Akuntansi Pemerintah (SAP) mendefinisikan "aset sebagai sumber daya ekonomi yang dikuasasi dan/atau dimiliki oleh pemerintah sebagai akibat peristiwa masa lalu dan dari mana manfaat ekonomi dan/atau sosial dimasa depan diharapkan dapat diperoleh baik oleh pemerintah maupun masyarakat serta dapat diukur dalam satuan mata uang, termasuk sumber daya non keuangan yang diperlukan untuk menyediakan jasa bagi masyarakat umum dan sumber-sumber daya yang dipelihara karena alasan sejarah dan budaya”.

Istilah aset dapat berarti kekayaan (harta kekayaan) atau aktiva atau properti, dalam terminologi akuntansi, aset adalah sumber daya yang dimiliki dan/atau dikuasai oleh suatu badan usaha atau pemerintah secara historis dan manfaat ekonomi dan/atau sosial dimasa depan diharapkan dapat diperoleh, serta dapat diukur dalam satuan uang. Aset daerah meliputi aset keuangan seperti kas, saham dan obligasi, aset fisik seperti tanah, infrastruktur dan aset bergerak, dan aset tak berwujud seperti, aset fisik yaitu aset tetap tanah atau aset real estate, yang merupakan sebagian besar dari aset daerah, disamping infrastruktur seperti bangunan, pasokan air dan sistem yang terkait, jaringan, jalan, pembangkit listrik dan sistem peralatan, transportasi dan komunikasi. 


\section{BAB III METODE PENELITIAN}

\section{Teknik Analisis Data dan Penyusunan Kesimpulan.}

Teknik analisis data yang digunakan dalam penelitian ini adalah uji komponen Sistem Pengendalian Intern atas pengelolaan aset tetap daerah pada Badan Pengelolaan Keuangan dan Aset Daerah Kota Sorong.

Langkah-langkah dalam uji komponen Sistem Pengendalian Intern sebagai berikut:

1. Melakukan wawancara kepada petugas/pejabat yang terkait dengan fungsi pengelolaan aset tetap

2. Melakukan pengamatan atas kegiatan pengelolaan aset tetap.

Penelitian ini akan menghasilkan sebuah kesimpulan dan rekomendasi. Pola pengambilan kesimpulan adalah sebagai berikut:

$\begin{array}{ccc}\text { Observasi } & \text { Temuan } & \text { Kesimpulan } \\ \text { Wawancara } & \text { Temuan } & \text { Kesimpulan } \\ \text { Kuesioner } & \text { Temuan } & \text { Kesimpulan }\end{array}$

\section{BAB IV \\ PEMBAHASAN}

Laporan Keuangan Badan Pengelolaan Keuangan Dan Aset Daerah Kota Sorong Tahun 2015 merupakan laporan yang mencakup seluruh aspek keuangan yang dikelola Badan Pengelola Keuangan Dan Aset Daerah Kota Sorong Periode 31 Desember 2015 dan 2014 yang disusun dan disajikan dengan berpedoman pada Peraturan Pemerintah Nomor 71 Tahun 2010 Lampiran I tentang standar Akuntansi Pemerintah yang terdiri dari:
a. Laporan Realisasi Anggaran (LRA);
b. Neraca; dan
c. Catatan atas Laporan Keuangan (CaLK)

Maksud dan Tujuan Penyusunan Laporan Keuangan, Badan Pemeriksaan Keuangan Dan Aset Daerah Kota Sorong Tahun 2015 adalah:

1. Sebagai sarana pertanggungjawaban dari Kepala Daerah, atas pelaksanaan Anggaran dan Pendapatan Belanja Daerah.

2. Memberikan informasi tentang Laporan Keuangan bagi pengguna Laporan Keuangan Pemerintah Kota Sorong.

3. Wujud akuntabilitas dan transparansi dalam pengelolaan keuangan daerah, untuk mewujudkan tata kelola pemerintahan yang baik.

\section{Landasan Hukum Penyusunan Laporan Keuangan}

Landasan hukum penyusunan laporan keuangan Tahun 2015 meliputi:

1. Undang-undang Nomor 17 Tahun 2003 tentang Keuangan Negara

2. Undang-undang Nomor 1 Tahun 2004 tentangPerbendaharaan Negara

3. Undang-undang Nomor 32 Tahun 2004 tentang Pemerintahan Daerah

4. Undang-undang Nomor 33 Tahun 2004 tentang Perimbangan Keuangan antara Pemerintah Pusat dan Pemerintah Daerah

5. Peraturan Pemerintah Nomor 109 Tahun 2000 tentang Kedudukan Keuangan Kepala Daerah danWakil Kepala Daerah

6. Pearturan Pemerintah Nomor 25 Tahun 2000 tentang Kewenangan Pemerintah Pusat dan Kewenangan Pemerintah Provinsi sebagai Daerah Otonom

7. Peraturan Pemerintah Nomor 71 Tahun 2010 tentang Standar Akuntansi Pemerintah (SAP)

8. Peraturan Pmemerintah Nomor 58 Tahun 2005 tentang Pengelolaan Keuangan Daerah

9. Peraturan Menteri Dalam Negeri Nomor 5 Tahun 1997 tentang Tuntutan Perbendaharaan danTuntutan Ganti Rugi Keuangan dan Barang Daerah

10. Peraturan Menteri Dalam Negeri Nomor 64 Tahun 2013 tentang Penerapan Standar Akuntansi Pemerintah Berbasis Akrual pada Pemerintah Daerah.

\section{Hambatan dan Kendala dalam Pencapaian Target Kinerja Keuangan}

Maksud dan Tujuan Penyusunan Laporan Keuangan 
Secara umum permasalahan yang masih dihadapi dalam pengelolaan pendapatan daerah yang tidak optimal antara lain:

a. Transparansi penetapan formula pengalokasian dana-dana dari luar DAU belum nyata (daerah kesulitan menentukan asumsi penerimaan untuk tahun yang akan datang)

b. Banyaknya dana dari pusat yang langsung diberikan kepada berbagai instansi sementara pemerintah Kota tidak diberi tahu berapa alokasi dana yang diberikan maupun peruntukannya.

c. Keunagan daerah masih sangat tergantung pada Pemerintah Pusat dengan prosentase PAD yang sangt kecil terhadap APBD.

Adapun Laporan Realisasi Anggaran:

Badan Pengelolaan Keuangan Dan Aset Daerah Kota Sorong memperoleh Anggaran Pendapatan dan Belanja Daerah untuk tahun anggaran 2015 secara keseluruhan sebesar $\mathrm{Rp}$ 1.251.872.462.190

Tabel 4.1

Anggaran Pendapatan dan Belanja Daerah Badan Pengelolaan Keuangan Dan Aset Daerah Kota Sorong Tahun Anggaran 2015

\begin{tabular}{|c|l|r|}
\hline No & \multicolumn{1}{|c|}{ Uraian } & $\begin{array}{c}\text { Anggaran } \\
\text { (Dalam Rupiah) }\end{array}$ \\
\hline 1 & Pendapatan & 129.885 .735 .033 \\
\hline 2 & $\begin{array}{l}\text { Belanja } \\
\text { Operasi }\end{array}$ & 749.786 .202 .002 \\
\hline 3 & $\begin{array}{l}\text { Belanja } \\
\text { Modal }\end{array}$ & 296.543 .148 .890 \\
\hline 4 & Pembiayaan & 75.657 .376 .265 \\
\hline \multicolumn{2}{|c|}{ Total } & $\mathbf{1 . 2 5 1 . 8 7 2 . 4 6 2 . 1 9 0}$ \\
\hline
\end{tabular}

Sumber Data: BPKAD Kota Sorong

Anggaran Pendapatan dan Belanja Daerah Badan Pengelolaan Keuangan Dan Aset Daerah Kota Sorong untuk tahun anggaran 2015 sebesar Rp 1.251.872.462.190 yang terdiri dari Anggaran Pendapatan sebesar Rp 129.885.735.033, Anggaran Belanja sebesar Rp 1.046.329.350.892, dan Anggaran Pembiayaan sebesar Rp 75.657.376.265. Realisasi pencapaian kinerja keuangan Badan Pengelolaan Keungan Dan Aset Daerah Kota Sorong selama tahun 2015 dapat dirinci sebagai berikut:
Tabel 4.2

Laporan Realisasi Anggaran pendapatan dan Belanja

Periode Sampai Dengan 31 Desember 2015

\begin{tabular}{|c|c|c|c|c|}
\hline $\mathbf{N}$ & Uraian & $\begin{array}{c}\text { Anggaran } \\
2015 \\
\text { (Dalam } \\
\text { Rupiah) } \\
\end{array}$ & $\begin{array}{c}\text { Realisasi } \\
2015 \\
\text { (Dalam } \\
\text { Rupiah) }\end{array}$ & $(\%)$ \\
\hline 1 & $\begin{array}{l}\text { PENDAPA } \\
\text { TAN }\end{array}$ & $\begin{array}{r}129.885 .73 \\
5.033\end{array}$ & $\begin{array}{r}86.223 .38 \\
1.936\end{array}$ & $\begin{array}{l}66 . \\
38\end{array}$ \\
\hline & $\begin{array}{l}\text { Pendapatan } \\
\text { Pajak } \\
\text { Daerah }\end{array}$ & $\begin{array}{r}32.904 .000 \\
.000\end{array}$ & $\begin{array}{r}28.315 .95 \\
7.418\end{array}$ & $\begin{array}{l}86 . \\
06\end{array}$ \\
\hline & $\begin{array}{l}\text { Pendapatan } \\
\text { Retribusi } \\
\text { Daerah }\end{array}$ & $\begin{array}{r}22.221 .555 \\
.000\end{array}$ & $\begin{array}{r}11.103 .11 \\
1.775\end{array}$ & $\begin{array}{l}49 . \\
97\end{array}$ \\
\hline & $\begin{array}{l}\text { Hasil } \\
\text { Pengelolaan } \\
\text { Kekayaan } \\
\text { Daerah yang } \\
\text { Dipisahkan }\end{array}$ & $\begin{array}{r}1.723 .769 . \\
958\end{array}$ & $\begin{array}{r}741.637 .3 \\
42\end{array}$ & $\begin{array}{l}43 . \\
02\end{array}$ \\
\hline & $\begin{array}{l}\text { Lain-lain } \\
\text { PAD yang } \\
\text { sah }\end{array}$ & $\begin{array}{r}73.036 .410 \\
.075\end{array}$ & $\begin{array}{r}46.062 .67 \\
5.401\end{array}$ & $\begin{array}{l}63 . \\
07\end{array}$ \\
\hline 2 & BELANJA & $\begin{array}{r}1.046 .329 \\
350.892\end{array}$ & $\begin{array}{r}928.464 .4 \\
30.994\end{array}$ & $\begin{array}{c}88 . \\
69\end{array}$ \\
\hline & $\begin{array}{l}\text { Belanja } \\
\text { Operasi }\end{array}$ & $\begin{array}{r}749.786 .20 \\
2.002\end{array}$ & $\begin{array}{r}661.489 .2 \\
26.519\end{array}$ & $\begin{array}{l}88 . \\
22\end{array}$ \\
\hline & $\begin{array}{l}\text { Belanja } \\
\text { Modal }\end{array}$ & $\begin{array}{r}296.543 .14 \\
8.890 \\
\end{array}$ & $\begin{array}{r}266.975 .2 \\
04.475 \\
\end{array}$ & $\begin{array}{l}90 . \\
03\end{array}$ \\
\hline 3 & $\begin{array}{l}\text { PEMBIAY } \\
\text { AAN }\end{array}$ & $\begin{array}{r}75.657 .376 \\
.265\end{array}$ & $\begin{array}{r}78.320 .90 \\
1.784\end{array}$ & $\begin{array}{l}103 \\
.52\end{array}$ \\
\hline & $\begin{array}{l}\text { SURPLUS/ } \\
\text { DEFISIT }\end{array}$ & $\begin{array}{r}75.657 .376 \\
.265\end{array}$ & $\begin{array}{r}65.680 .68 \\
7.870\end{array}$ & $\begin{array}{l}86 . \\
81\end{array}$ \\
\hline
\end{tabular}

Sumber Data: BPKAD Kota Sorong

\section{Pendapatan}

Realisasi pendapatan daerah tahun 2015 mencapai hasil 66,38\% dari target yang ditetapkan, dan hal ini dicapai dari hasil penerimaan pendapatan asli daerah sebesar Rp 86.223.381.936 dari target sebesar $\mathrm{Rp}$ 129.885 .735 .033

\section{Belanja}

Realisasi belanja sampai dengan akhir tahun 2015 sebesar Rp 928.454.430.994 atau $172,25 \%$

\section{Pembiayaan}

Realisasi pembiayaan sampai dengan akhir tahun 2015 sebesar Rp 78.320.901.784 atau $103,52 \%$. Realisasi pembiayaan ini 
digunakan untuk pembayaran pokok piutang dan utang daerah.

Setelah menyususn LRA, perlu juga disusun Neraca, Neraca dibuat dengan maksud untuk mengetahui posisi keuangan BPKAD atau Pemerintah Kota Sorong untuk tahun 2015 mengalami pengurangan jumlah aset tetap dari tahun sebelumnya atau pada tahun 2014. Berikut ini adalah tabel neraca Badan Pengelolaan Keuangan Dan Aset Daerah Kota Sorong: 
Tabel 4.3

Pemerintah Kota Sorong

NERACA

Per 31 Desember 2015 Dan 2014

\begin{tabular}{|c|c|c|c|}
\hline No & Uraian & 2015 & 2014 \\
\hline & ASET & & \\
\hline & ASET LANCAR & & \\
\hline & Kas & 0.00 & 6.775 .659 \\
\hline & Piutang Retribusi & 0.00 & 0.00 \\
\hline & Piutang Lain-lain & 77.869 .117 .127 & 32.903 .255 .628 \\
\hline & Persediaan & 5.272 .638 .429 & 8.537.375.173 \\
\hline & JUMLAH ASET LANCAR & 83.132.016.952 & 90.179 .005 .421 \\
\hline & INVESTASI JANGKA PANJANG & & \\
\hline & Investasi Nonpermanen & 0.00 & 0.00 \\
\hline & Investasi Permanen & 12.456 .500 .000 & 12.456.500.000 \\
\hline & JUMLAH INVESTASI JANGKA & 12.465 .500 .000 & 12.256 .500 .000 \\
\hline & PANJANG & & \\
\hline & ASET TETAP & 202.771 .396 .495 & 183.793 .157 .375 \\
\hline & Tanah & 198.169 .474 .676 & 184.984 .280 .697 \\
\hline & Peralatan dan Mesin & 789.336 .000 .434 & 682.137 .971 .249 \\
\hline & Gedung dan Bangunan & 1.086.675.385.986 & 938.313 .011 .061 \\
\hline & Jalan, Irigasi, dan Jaringan & 27.153 .620 .625 & 26.716 .820 .625 \\
\hline & Aset tetap lainnya & 97.883 .459 .592 & 44.661 .106 .514 \\
\hline & Konstruksi Dalam Pengerjaan & (739.949.928.489) & 0.00 \\
\hline & Akumulasi Penyusutan & 1.659.039.409.319 & 2.060.606.347.521 \\
\hline & JUMLAH ASET TETAP & & \\
\hline & ASET LAINNYA & 65.298 .304 .791 & 65.296 .304 .791 \\
\hline & $\begin{array}{l}\text { Aset lain-lain } \\
\text { IUMLAH ASET LAINNYA }\end{array}$ & 65.298.304.791 & 65.298.304.791 \\
\hline & JUMLAH ASET & 1.819 .935 .231 .062 & 2.228.311.687.832 \\
\hline \multirow[t]{4}{*}{2} & KEWAJIBAN & & \\
\hline & Kewajiban Jangka Pendek & 91.082 .153 .121 & 38.844 .849 .327 \\
\hline & Kewajiban Jangka Panjang & 0.00 & 0.00 \\
\hline & JUMLHA KEWAJIBAN & 91.082.153.121 & 38.844.849.327 \\
\hline \multirow[t]{15}{*}{3} & EKUITAS DANA & & \\
\hline & EKUITAS DANA LANCAR & & \\
\hline & Pendapatan yang ditangguhkan & 0.00 & 6.775 .659 \\
\hline & Cadangan Piutang & 0.00 & 10.679.093.898 \\
\hline & Cadangan Persediaan & 0.00 & 8.537.375.173 \\
\hline & JUMLAH EKUITAS DANA & 0.00 & 51.334.375.173 \\
\hline & LANCAR & & \\
\hline & EKUITAS DANA INVESTASI & 0.00 & 12.465 .500 .000 \\
\hline & Diinvestasikan dalam jangka panjang & 0.00 & 2.060.606.347.521 \\
\hline & Diinvestasikan dalam asset tetap & 0.00 & 65.060 .834 .890 \\
\hline & Diinvestasikan dalam asset lainnya & 0.00 & 2.138.132.682.411 \\
\hline & JUMLKAH EKUITAS DANA & & \\
\hline & INVESTASI & & 2.189.466.838.505 \\
\hline & 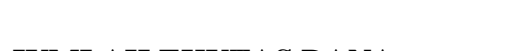 & 1.728.835.077.941 & \\
\hline & $\begin{array}{l}\text { JUMLAH EKUTAS DANA } \\
\text { JUMLAH EKUITAS }\end{array}$ & & \\
\hline \multicolumn{2}{|c|}{$\begin{array}{l}\text { JUMLAH KEWAJIBAN DAN EKUITAS } \\
\text { DANA }\end{array}$} & 1.819.935.231.062 & 2.228.311.687.832 \\
\hline
\end{tabular}

Sumber Data : BPKAD Kota Sorong 
Aset Tetap

$\underline{31 \text { Desember } 2015}$

Rp 1.659.039.409.319

31 Desember 2014

Rp 2.060.606.347.521

Rincian aset tetap Pemerintah Kota Sorong pada Badan Pengelolaan Keuangan Dan Aset Daerah sebagai berikut:

Tabel 4.4

Rincian Aset Tetap

\begin{tabular}{|c|c|c|c|}
\hline Jenis Aset & $\begin{array}{l}31 \text { Desember } \\
2015 \\
(\text { Rp) }\end{array}$ & $\begin{array}{c}31 \text { Desember } \\
2014 \\
(\text { Rp) }\end{array}$ & $\begin{array}{c}\text { Bertam } \\
\text { bah / } \\
\text { Berkur } \\
\text { ang } \\
\text { (Rp) }\end{array}$ \\
\hline Tanah & 202.771 .396 .459 & $\begin{array}{r}183.739 .157 .3 \\
75\end{array}$ & $\begin{array}{r}18.978 .2 \\
39.120\end{array}$ \\
\hline $\begin{array}{l}\text { Peratan dan } \\
\text { Mesin }\end{array}$ & 198.169.474.676 & $\begin{array}{r}184.984 .280 .6 \\
97\end{array}$ & $\begin{array}{r}13.185 .1 \\
93.979 \\
\end{array}$ \\
\hline $\begin{array}{l}\text { Gedung dan } \\
\text { Bangunan }\end{array}$ & 786.336 .000 .434 & $\begin{array}{r}682.137 .971 .2 \\
49 \\
\end{array}$ & $\begin{array}{r}104.198 . \\
029.185 \\
\end{array}$ \\
\hline $\begin{array}{l}\text { Jalan, Irigasi dan } \\
\text { Jaringan }\end{array}$ & $\begin{array}{r}1.086 .675 .385 .98 \\
6\end{array}$ & $\begin{array}{r}398.313 .011 .0 \\
61\end{array}$ & $\begin{array}{l}148.362 . \\
374.925 .\end{array}$ \\
\hline $\begin{array}{l}\text { Aset Tetap } \\
\text { Lainnya }\end{array}$ & 27.153 .620 .625 & $\begin{array}{r}26.716 .820 .62 \\
5 \\
\end{array}$ & $\begin{array}{r}436.800 . \\
000 \\
\end{array}$ \\
\hline $\begin{array}{l}\text { Konstruksi } \\
\text { Dalam } \\
\text { Pengerjaan }\end{array}$ & 97.883 .459 .592 & $\begin{array}{r}44.661 .106 .51 \\
4\end{array}$ & $\begin{array}{r}53.222 .3 \\
53.078\end{array}$ \\
\hline $\begin{array}{l}\text { Akumulasi } \\
\text { Penyusutan }\end{array}$ & (739.949.928.489) & 0.00 & $\begin{array}{r}(739.94 \\
9.928 .48 \\
9)\end{array}$ \\
\hline Jumlah & $\begin{array}{r}1.659 .039 .409 .31 \\
9\end{array}$ & $\begin{array}{r}2.060 .606 .347 \\
.521\end{array}$ & $\begin{array}{r}(401.56 \\
6.938 .20 \\
2) \\
\end{array}$ \\
\hline
\end{tabular}

Sumber Data: BPKAD Kota Sorong

\section{BAB V \\ KESIMPULAN DAN SARAN}

\section{Kesimpulan}

Berdasarkan pembahasan dan hasil kuesioner serta wawancara yang penulis lakukan pada BPKAD Kota Sorong maka dapat diambil kesimpulan bahwa:

1. Penerapan system pengendalian intern atas pengelolaan aset daerah pada BPKAD Kota Sorong sudah diterapkan namun belum optimal, alasannya karena masih ada hambatan dan kendala yang dialami dari setiap unsur komponen sistem pengendalian intern yaitu:

a. Aktivitas Pengendalian

b. Penilaian Resiko c. Lingkungan Pengendalian

d. Informasi dan komunikasi; dan

e. Pemantauan

2. Jumlah hasil keseluruhan pada neraca BPKAD Kota Sorong tahun 2015 sebesar Rp 1. 819.935.231.062 telah mengalami penurunan yang tidak terealisasikan sebesar $\mathrm{Rp}$ 401.566.938.202 dimana pada tahun 2014 jumlah hasil keseluruhan sebesar Rp 2.228.311.687.832

\section{Saran}

Saran-saran yang dapat diberikan oleh peneliti kepada Inspektorat dan Badan Pengelolaan Keuangan Dan Aset Daerah (BPKAD) Kota Sorong adalah sebagai berikut:

1. Kepada Inspektorat dan Badan Pengelolaan Keuangan dan Aset Daerah untuk dapat lebih serius dan fokus dalam mengatasi permasalahan utama yang ada di instansi, dengan melakukan usulan-usulan perbaikan. Kerena apabila Inspektorat selaku pengawas dan Badan Pengelolaan Keuangan dan Aset Daerah selaku pengelola bila tidak serius untuk mengatasi permasalahan ini, maka akan memberi kerugian yang signifikan bagi Inspektorat dan BPKAD bahkan pemerintah daerah.

2. Dalam rangka meningkatkan produktivitas sumber daya manusia yang ada didalam Pemerintahan.

3. Pimpinan di Inspektorat dan BPKAD agar membuat aturan tertulis terkait kode etik yang dapat dijadikan acuan dan memberi efek jera kepada pegawai bahkan pimpinan sendiri ketika tidak disiplin pada jam masuk kantor.

4. Ketika ada rekomendasi dari BPK kepada BPKAD bahkan di seluru SKPD maka segera ditindaklanjuti.

5. Pimpinan di BPKAD harus memberikan sanksi yang tegas kepada pegawai yang tidak mempunyai kemauan dalam bekerja dan harus mengarahkan bendahara barang agar melakukan penelusuran atau pengecekan secara teratur karena aset tidak di data dengan baik khususnya aset kendaraan beroda dua dan roda empat yang sampai saat ini tidak diketahui keberadaannya, selain itu harus tertib dalam melakukan pencatatan nomor BPKB dan 
STNK dan harus melakukan penelusuran kendaraan dinas yang secara langsung di ganti nomon DS atau plat.

6. Harus ada kebijakan dari kepala daerah dan DPRD untuk mengeluarkan peraturan daerah bahkan melakukan penghapusan aset di pemerintah Kota Sorong.

7. Pimpinan di BPKAD bagian aset serta pegawai harus saling bekerja sama dalam mengelola aset serta pimpinan juga harus mengadakan pertemuan dengan seluruh bendahara barang di SKPD agar tidak terjadi keterlambatan data dan kesalahan yang masih terjadi di setiap SKPD terkait dengan kesalahan pencatatan, pengkodean bahkan penggolongan data aset.

8. Pimpinan di BPKAD bagian aset harus melakukan komunikasi yang efektif dengan bendahara barang di seluruh SKPD agar para bendahara bisa bekerja dengan serius agar menyampaikan bahkan menyerahkan data yang dibutuhan oleh BPKAD bisa tepat waktu.

9. Dalam proses pencatatan atau perlakuan aset tetap yang dilakukan di BPKAD bagian aset tetap diharapkan berdasarkan kondisi aset rill yang dimiliki oleh instansi agar dapat melakukan pencatatan dan pengecekan aset tetap dengan teliti, baik dan benar sehingga tidak terjadi kesalahan dan penurunan jumlah nilai aset terutama pada aset tetap.

\section{DAFTAR PUSTAKA}

Amin Tunggal Widjaja, 2003 "Pengukuran Kinerja dengan Balanced Scorecard. Harvarindo". Jakarta.

Bastian, 2013, "Audit Kinerja Pada Sektor Publik".

Champion, Dean J. 1990 "Basic Statistik For Social Research", San Fransisco, Chandler Publisher.

Halim, 2007, "Pengaruh Managemen Aset Terhadap Optimalisasi".

Mulyadi, 2001. Sistem Akuntansi. STIE YKPN. Yogyakarta.

Nugroho Widjajanto, 2001 "Sistem Informasi Akuntansi". Erlangga: Jakarta

Peraturan Menteri Dalam Negeri Nomor 59 Tahun 2007 tentang Perubahan Permendagri Nomor 13 Tahun 2006.
Peraturan Menteri dalam Negeri Republik Indonesia Nomor 17 Tahun 2007 tentang Pedoman Teknis Pengelolaan Barang Milik Daerah.

Peraturan Pemerintah Republik Indonesia Nomor 60 Tahun 2008 tentang Sistem Pengendalian Intern Pemerintah.

Putri Rustam 2011 "Analisis SIstem Pengendalian Intern Pengelolaan Asset Daerah di BPKAD Pemerintah Kabupaten Tulugagung". Jurnal Universitas Brawijaya Malang.

Ritonga, Irwan Taufiq. 2011 "Akuntansi Pemerintah Daerah". Sekolah Pascasarjana UGM. Yogyakarta.

Suwardjono, 2008. "Teori Akuntansi Perekayasaan Pelaporan Keuangan". BPFE.Yogyakatra.

Undang-undang Nomor 32 Tahun 2004 tentang Pemerintahan Daerah.

Undang-undang Nomor 33 tahun 2004 tentang Perimbangan Keuangan Pemerintah Pusat dan Daerah.

Yin Robert K. 2008 "Studi Kasus Desain dan Metode. Rajawali Pers, Jakarta. 